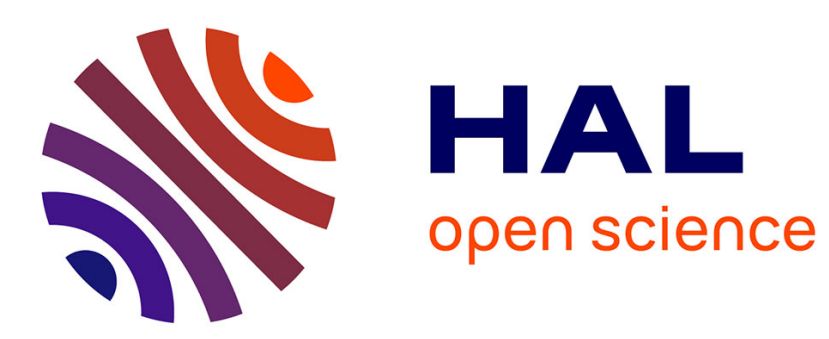

\title{
RESISTIVITY OF TERNARY CHEVREL-PHASE SUPERCONDUCTORS
}

\author{
Roland Martin, K. Mountfield, L. Corruccini
}

\section{To cite this version:}

Roland Martin, K. Mountfield, L. Corruccini. RESISTIVITY OF TERNARY CHEVRELPHASE SUPERCONDUCTORS. Journal de Physique Colloques, 1978, 39 (C6), pp.C6-371-C6-372. 10.1051/jphyscol:19786165 . jpa-00217578

\section{HAL Id: jpa-00217578 https://hal.science/jpa-00217578}

Submitted on 1 Jan 1978

HAL is a multi-disciplinary open access archive for the deposit and dissemination of scientific research documents, whether they are published or not. The documents may come from teaching and research institutions in France or abroad, or from public or private research centers.
L'archive ouverte pluridisciplinaire HAL, est destinée au dépôt et à la diffusion de documents scientifiques de niveau recherche, publiés ou non, émanant des établissements d'enseignement et de recherche français ou étrangers, des laboratoires publics ou privés. 


\section{RESISTIVITY OF TERNARY CHEVREL-PHASE SUPERCONDUCTORS}

R. Martin, K.R. Mountfield, and L.R. Corruccini

Physics Department University of California at Davis, Davis, Califormia 95616, USA

Résumé.- Nous avons avons mesuré la résistivité entre $4.2 \mathrm{~K}$ et $400 \mathrm{~K}$ d'une série de phases de Chevrel qui sont des composés supraconducteurs. Tous montrent une courbure très négative $\left(\mathrm{d}^{2} \mathrm{p} / \mathrm{dT}^{2}\right)$ au-dessus d'environ $60 \mathrm{~K}$, semblable à ce qu'on observe dans les composés $\mathrm{A}-15$. Les résistivités à la température ambiante sont élevêes, de $I^{\prime}$ ordre de $10^{-3} \Omega \mathrm{cm}$.

Abstract. We have measured the resistivities of a series of superconducting Chevre1-phase compounds from $4.2 \mathrm{~K}$ to $400 \mathrm{~K}$. All show strong negative curvature $\mathrm{d}^{2} \rho / \mathrm{dT}^{2}$ above about $60 \mathrm{~K}$, similar to that observed in the $\mathrm{A}-15$ compounds. Room temperature resistivities are high, in the $10^{-3} \Omega \mathrm{cm}$ range.

Recent interest has developed in the deviations from linearity in the resistivity $\rho(T)$ of transition-metal superconductors. In particular a number of the A-15 compounds exhibit a negative curvature $\frac{\mathrm{d}^{2} \rho}{\mathrm{dT}^{2}}$ at high temperatures, including $\mathrm{Nb}_{3}$ $\mathrm{Sn}, \mathrm{Nb}_{3} \mathrm{Sb}, \mathrm{V}_{3} \mathrm{Si}$, and $\mathrm{V}_{3} \mathrm{Ge}$. The data do not appear to approach a linear temperature dependence at high $\mathrm{T}$, as expected from the Bloch-Grüneisen Theory. Woodard and Cody /1/ and Williamson and Milewits $/ 2 /$ have pointed out that an exponential. term $e^{-T_{0} / T}$ can be used to fit the data; Fisk and Webb /3/ and Wiesmann et a1. /4/ have suggested that $\rho(T)$ may "saturate" at high $T$ when the electron mean free path becomes comparable to the lattice spacing. In the latter case the lattice spacing imposes a lower bound for the mean free path and a maximum for $\rho$.

We have measured the resistivity in a series of superconducting ternary Chevrel phase compounds $M_{1} .2^{M_{6}} X_{8}$, where $M$ is a metal and $X$ is either $\mathrm{S}$ or $\mathrm{Se}$, and find a similar negtive curvatu$r e$ in $\rho(T)$ in these materials. Measurements were made on compressed, sintered pellets reacted in an inert gas atmosphere, using a standard four probe DC method. To date, single crystals of these compounds large enough for resistivity measurements have not been synthesized.

Representative results of $\rho$ vs. T the nonmagnetic compound $\mathrm{Pb}_{1.2} \mathrm{Mo}_{6} \mathrm{Se}_{8}$ are shown in figure 1. The results for $\mathrm{Pb}_{1,2} \mathrm{Mo}_{6} \mathrm{~S}_{8}, \mathrm{Sn}_{1.2} \mathrm{Mo}_{6} \mathrm{~S}_{8}, \mathrm{Sn}_{1.2}$ $\mathrm{Mo}_{6} \mathrm{Se}_{8}, \mathrm{La}_{1.2} \mathrm{Mo}_{6} \mathrm{~S}_{8}$ and $\mathrm{La}_{1.2} \mathrm{Mo}_{6} \mathrm{Se}_{8}$ are qualitatively similar, as are compounds where $M$ is one of the rare earth elements Gd, Dy, or Sm. The resistivities for all these compounds show negative cur- vature above about $60 \mathrm{~K}$. Resistivity ratios $\rho_{300}$ $/ \rho 15$ are typically about 2.5 , but range as high as 10. The data can be fit above $40 \mathrm{~K}$ within a rms deviation of 1 to $2 \%$ by either the saturation resistivity model of Wiesman et al. or by an exponential dependence on $1 / T$. The model of Wiesmann et al. assumes that the total resistivity of the system is given by the electron-phonon resistivity $\rho_{\text {ideal }}(\mathrm{T})$ shunted by the 1 imiting resistivity $\rho_{\max }$ : $\frac{1}{\rho}=\frac{1}{\rho_{\text {ideal }}}(\mathrm{T})+\frac{1}{\rho_{\max }}$. Here $\rho_{\text {ideal }}$ is assumed to have the form $\gamma+\rho_{1} T$, where $\gamma$ and $\rho_{1}$ are constants. For the compounds studied, $\rho_{\max } / \rho_{300}$ is typically equal to about 1.5 , suggesting that there is relatively little further change in resistivity above room temperature.

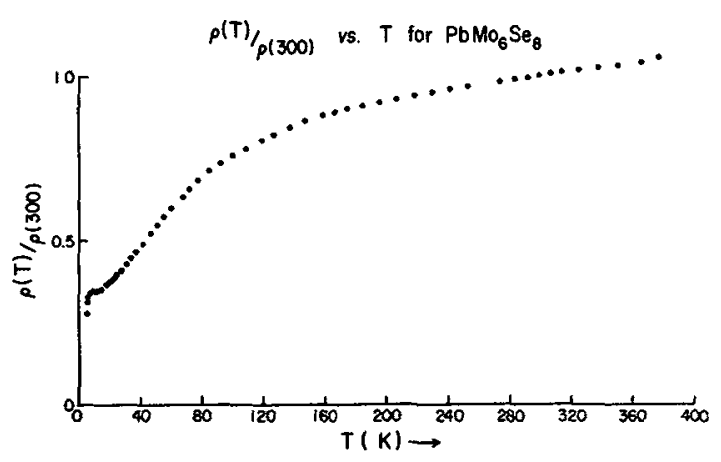

Fig. 1 : Resistivity of $\mathrm{Pb}_{1}, 2^{\mathrm{MO}_{6}} \mathrm{Se}_{8}\left(\rho_{300}=\right.$ $1.8 \mathrm{~m} \Omega \mathrm{cm}$ ) representative of the compounds studied. curvature is negative above about $60 \mathrm{~K}$. 
Fitted to an empirical exponential relation of the form $\rho(T): a+b T+d e^{-T_{0} / T}$, these compounds have discussed various physical interpretations of this thermally activated resistivity.

The room temperature resistivities of all ternary compounds studied were high, typically $2-10 \mathrm{~m} \Omega-\mathrm{cm}$. This value is somewhat sensitive to the method of sample preparation and grain size, but in all cases it was found to exceed $1.8 \mathrm{~m} \Omega-\mathrm{cm}$. These values are roughly tem times higher than those found in A-15 superconductors /3/. It is not clear how much of the measured resistivity is due to contact resistance between grains in the compressed samples. However, AC resistivity measurements on two samples at 10 and $100 \mathrm{kHz}$ at $300 \mathrm{~K}$ and $77 \mathrm{~K}$ were identical to the $D C$ results, suggesting that the impedance between grains is resistive in character, and probably not large in comparison with the bulk resistivity. Residual resistivity below $T_{c}$ was unobservably sma11. At low temperatures above $T_{c}$, the measured resistivities were in good agreement with estimates obtained from electron mean free paths derived from critical field measurements $15 /$.

$$
\text { C.Y. Fong /6/ has suggested that the large }
$$

values of $\rho_{300}$ are an intrinsic bulk property of the Chevrel phase, due to the channeling effect of the Mo-Mo bonds on the conduction electron motion. Because the conduction d orbitals of adjacent Mo atoms are canted with respect to each other, the electrons must scatter through an angle of about $70^{\circ}$ to move from one atom to the next. This results in a factor of $\cos \left(70^{\circ}\right) \simeq \frac{1}{3}$ in the matrix element used to calculate the collision term in the transport equation. Aside from this, the situation is similar to that found in A-15 compounds, where the conduction is along the d-orbitals of the transition metal ions, which are aligned in linear chains. In this model the Chevrel phase conductivity would be lower than A-15 compound conductivity by a factor of $\cos ^{2}\left(70^{\circ}\right) \simeq \frac{1}{10}$, in agreement with our observations.

We are indebted to Dr. R.N. Shelton for supplying us with the Chevre1-phase compounds.

\section{References}

/1/ Woodard, D.W., and Cody, G.D., Phys. Rev. A 136 (1964) 166 .

$12 /$ Williamson, S.J. and Milewits, M. in Proceedings of the Second Rochester Conference on Superconductors in $\mathrm{d}-$ and $\mathrm{f}$ - band Metals. Rochester, N.Y. 1976, ed. D.H. Douglass, p.551.

/3/ Fisk, Z. and Webb, G.W., Phys. Rev. Lett. 36 (1976) 1084.

14/ Wiesmann, H., Gurvitch, M., Lutz, H., Ghosh, A., Schwartz, B., Strongin, M., Allen, P.B., and Halley, J.W. Phys. Rev. Lett. 38 (1977) 782 .

/5/ Fischer, 0., Decroux, M., Chevrel, R., Proc. Second Rochester Conference on Superconductivity in $d-$ and $f-$ Band Metals, Rochester, 1976, p; 175 (Plenum Press).

/6/ Fong, C.Y. private communication. 